\title{
Acetylation of lignin containing microfibrillated cellulose and its reinforcing effect for polylactic acid
}

DOI:

10.1016/j.eurpolymj.2020.109803

\section{Document Version}

Accepted author manuscript

Link to publication record in Manchester Research Explorer

\section{Citation for published version (APA):}

Yeti, F., Liu, X., Sampson, W. W., \& Gong, R. H. (2020). Acetylation of lignin containing microfibrillated cellulose and its reinforcing effect for polylactic acid. European Polymer Journal, 134, 109803.

https://doi.org/10.1016/j.eurpolymj.2020.109803

\section{Published in:}

European Polymer Journal

\section{Citing this paper}

Please note that where the full-text provided on Manchester Research Explorer is the Author Accepted Manuscript or Proof version this may differ from the final Published version. If citing, it is advised that you check and use the publisher's definitive version.

\section{General rights}

Copyright and moral rights for the publications made accessible in the Research Explorer are retained by the authors and/or other copyright owners and it is a condition of accessing publications that users recognise and abide by the legal requirements associated with these rights.

\section{Takedown policy}

If you believe that this document breaches copyright please refer to the University of Manchester's Takedown Procedures [http://man.ac.uk/04Y6Bo] or contact uml.scholarlycommunications@manchester.ac.uk providing relevant details, so we can investigate your claim.

\section{OPEN ACCESS}




\title{
Acetylation of Lignin Containing Microfibrillated
}

\section{Cellulose and Its Reinforcing Effect for Polylactic}

\section{Acid}

Ferhat Yetiş, Xuqing Liu, William W. Sampson, and R. Hugh Gong*

Department of Materials, University of Manchester, Oxford Road, Manchester, M13 9PL, UK

*Corresponding author: hugh.gong@manchester.ac.uk

\begin{abstract}
High hemicellulose and lignin content MFC (MFLC) was isolated from chemithermomechanical pulp (CTMP), and surface acetylation used to significantly decrease its polarity. This modification of MFLC provided good dispersibility in PLA when used for biocomposites fabrication via a solvent casting method. MFLC exhibited higher modification efficiency compared to lignin-free MFC. Base-catalysed surface acetylation unchanged the crystalline structure of MFLC. Detection of the hydrogen bond between acetylated MFLC (AcMFLC) and PLA confirmed its role in improvement of the mechanical performance, thermal properties and crystallinity of the biocomposite with Ac-MFLC acting as an effective reinforcing and nucleating agent. The approach confirms the suitability of surface functionalization of MFLC for fabrication of biocomposites for a wide range of applications such as packaging and biomedical products.
\end{abstract}

Keywords: Microfibrillated lignocellulose, Surface modification, Acetylation, Biocomposites, Polylactic acid

Author E-mails: ferhat.yetis@postgrad.manchester.ac.uk

xuqing.liu@manchester.ac.uk

william.sampson@manchester.ac.uk 


\section{Introduction}

Awareness of environmental problems arising from petroleum-based polymers coupled with the diminishing petroleum resource and its increasing price have increased researcher's attention to biodegradable polymers. Polylactic acid (PLA) is a commercial biodegradable polymer produced from renewable sources, starch rich crops [1]. Due to its environmentally-friendly structure, low toxicity, biocompatibility and good transparency, it is attractive polymer to be 
used in the fabrication of packaging materials and biomedical implants [2,3]. To improve the durability of PLA based products and hence broaden its application areas, its inherent drawbacks such as low crystallization rate and thermal stability must be addressed $[4,5]$. Approaches reported in the literature include modification [6], copolymerization [7] and blending with other polymers [8]. An alternative approach, and the subject of the study presented here, is the addition of natural nano fibres and their derivatives to PLA. Microfibrillated cellulose (MFC), a precursor to nanofibrillated cellulose with some residual micron-scale fibrils isolated from wood or natural fibres using mechanical treatments, is a prominent candidate as reinforcement agent of PLA due to its unique properties such as high mechanical performance, large surface area, and biodegradability [9]. Its nanometer to submicron wide fibrils tend to form a web-like network and impart high strength to composites $[10,11]$. However, the strong polar nature of MFC restricts its dispersibility in non-polar media, which is the main challenge in the production of MFC reinforced composites. Abundant hydroxyl groups on the surface of MFC tend to form hydrogen bonds resulting in microfibril aggregation, which decreases the reinforcement of non-polar polymers. Surface modification increases the dispersibility of MFC in non-polar polymers by decreasing its polarity [12]. Among the various modification techniques, acetylation is a promising approach for the modification of MFC, since it is widely used for the modification of lignocellulosic sources

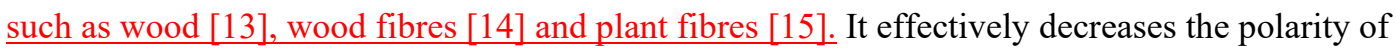
MFC, improving the mechanical performance [16] and thermal properties [17] by increasing interfacial adhesion between fibres and non-polar polymer matrix.

The usual approach is focused on the isolation of lignin-free MFC from delignified and bleached resources. Further, high hemicellulose and lignin containing raw materials include wood fibres [18-20], non-wood fibres [21-23], and commercial mechanical [24] and unbleached Kraft pulp fibres $[25,26]$ could be used for the isolation of lignin containing MFC (MFLC) that has gained attention due to its high yield, low production cost and low environmental impact [27]. However, it is still difficult to obtain good interfacial adhesion 
between MFLC and non-polar polymer matrix in composite applications although hemicellulose and lignin content slightly decrease the polarity of MFLC [28]. Therefore, surface treatment or modification is necessary to improve the compatibility of MFLC in non-polar polymer matrices. Moreover, MFLC could allow a high degree of modification as its surface is covered with highly accessible hemicellulose and lignin, which have highly branched semi-crystalline and totally amorphous structures, respectively.

Here, we isolated MFLC from chemi-thermomechanical pulp (CTMP) fibres, and modified its surface using simple base-catalysed transesterification method to increase its dispersibility and interfacial adhesion with PLA for fabrication of biocomposite films with high mechanical and thermal properties. We also modified the surface of lignin-free MFC to compare the modification efficiency with MFLC. It is expected that the highly reactive hydroxyl groups in the chemical structure of MFLC will lead to an increase in the modification efficiency, improving the properties of the final biocomposite products to be used in various industrial applications.

\section{Experimental Section}

\subsection{Materials}

PLA (Ingeo ${ }^{\mathrm{TM}}$ Biopolymer 4043D) was supplied by NatureWorks LLC (USA). PLA has a density of $1.24 \mathrm{~g} \mathrm{~cm}^{-3}$ and average molecular weight of $1.3 \times 10^{5} \mathrm{~g} \mathrm{~mol}^{-1}$. CTMP with $27 \%$ lignin (Table S1) was supplied by SCA (Sweden). Acetic anhydride and dimethylformamide (DMF) were purchased from Acros Organics (UK). Anhydrous potassium carbonate, chloroform, acetone and ethanol were purchased from Fischer Scientific (UK). All chemicals were reagent grade and used without any further purification.

\subsection{MFLC Preparation}

CTMP was soaked into water overnight before refining, carried out using a Medway beater (Reed Paper, UK) for 30 min. The refined pulp was screened using a Sommerville Fractionator 
fitted with a 200 mesh, corresponding to approximately $76 \mu \mathrm{m}$ hole size. The fine material passing through the mesh was collected on a muslin cloth and then further fibrillated using a homogenizer (IKA T18) at $20000 \mathrm{rpm}$ for $1 \mathrm{~h}$.

\subsection{MFLC Acetylation}

Acetylation was carried out following procedure described by Çetin et al. [29]. The reaction was carried out in a three-necked round-bottomed flask equipped with condenser under nitrogen flow. Fig. 1 shows the schematic representation of the acetylation process. $2 \mathrm{~g}$ freeze-dried MFLC was homogenized in DMF (100 ml) for $2 \mathrm{~min}$, and then transferred into a three-necked round-bottomed flask containing $\mathrm{K}_{2} \mathrm{CO}_{3}(0.3 \mathrm{~g})$ and acetic anhydride $(6 \mathrm{ml})$. The suspension was mixed and heated at $90{ }^{\circ} \mathrm{C}$ for $1 \mathrm{~h}$. The reaction was terminated by adding $5 \mathrm{ml}$ deionized water. After cooling for 20 min, the suspension was centrifuged to remove excess chemicals, and rinsed first with deionized water $(200 \mathrm{ml})$ at $60{ }^{\circ} \mathrm{C}$ for $2 \mathrm{~h}$, and then with ethanol/acetone (50/50) mixture $(200 \mathrm{ml})$ at $60{ }^{\circ} \mathrm{C}$ for $2 \mathrm{~h}$. After rinsing with solvent, samples were solvent exchanged with water, and freeze-dried.

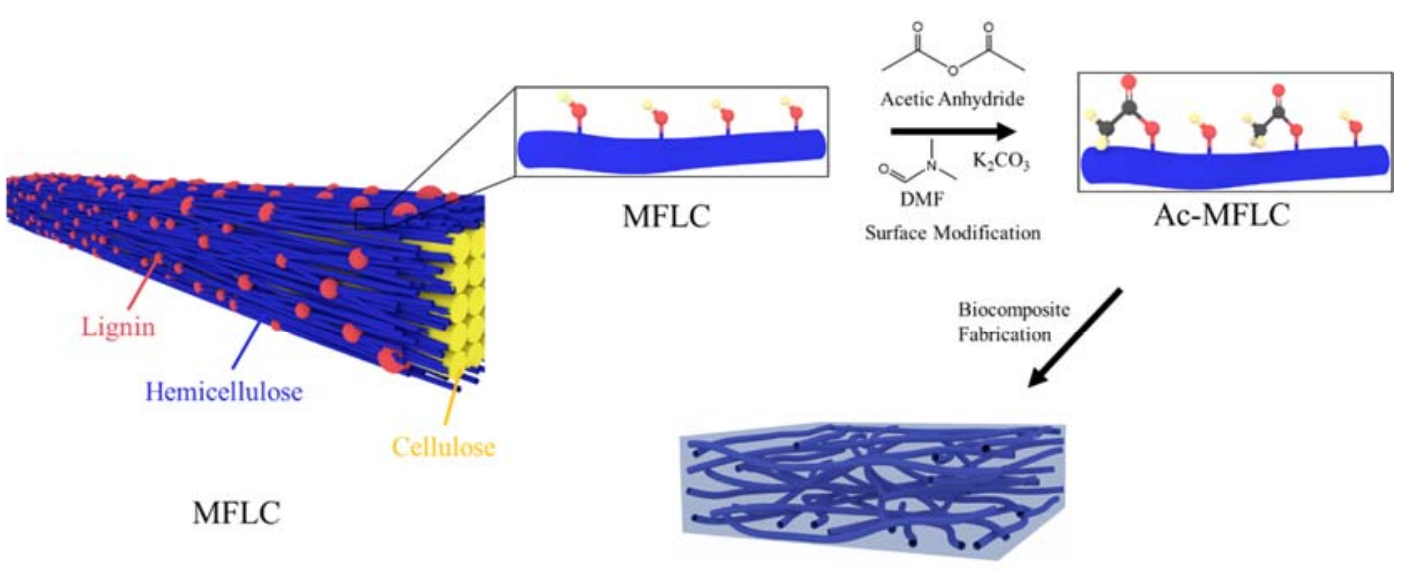

Ac-MFLC/PLA Biocomposite

Fig. 1. Schematic illustration of MFLC, its surface modification with acetic anhydride and AcMFLC biocomposites fabricated using solvent casting method.

\subsection{PLA Biocomposite Preparation}


PLA biocomposite films containing 0.5, 1, 1.5, 2.5 and $5 \%$ acetylated MFLC (Ac-MFLC) were prepared using a solvent casting method. PLA granules were firstly mixed with chloroform $\left(\mathrm{CHCl}_{3}\right)$ at room temperature until fully dissolved. The Ac-MFLC suspension in $\mathrm{CHCl}_{3}$ was sonicated (Qsonica-700) for 2 min and transferred into PLA solution. This Ac-MFLC/PLA suspension was mixed, sonicated, and then poured slowly into Petri dishes, taking care to avoid bubbles. The $\mathrm{CHCl}_{3}$ was evaporated off at room temperature overnight. Finally, biocomposite films were dried by vacuum oven at $40{ }^{\circ} \mathrm{C}$ for $48 \mathrm{~h}$ to eliminate the residual solvent. The thickness of biocomposites was around $50 \mu \mathrm{m}$, as measured with a digital platen micrometer (Messmer Instruments, UK).

\subsection{Characterization}

The morphology of the MFLC and Ac-MFLC was observed using scanning electron microscopy (SEM - Zeiss Ultra-55), operated at $1.5 \mathrm{kV}$ acceleration voltage and $5 \mathrm{~mm}$ working distance. MFLC in deionized water $(0.03 \%)$ and Ac-MFLC in $\mathrm{CHCl}_{3}(0.03 \%)$ were sonicated for $1 \mathrm{~min}$, and a droplet was deposited onto mica disc, and then with thin layer of gold. FTIR spectra of the MFLC and Ac-MFLC were determined by using Thermo Nicolet 5700 spectrometer in ATR mode, equipped with $1.5 \mathrm{~mm}$ contact area in diameter. The spectrum was recorded in the range of $4000-400 \mathrm{~cm}^{-1}$ at a resolution of $4 \mathrm{~cm}^{-1}$ for 32 scans per sample. X-ray diffraction (XRD) patterns of MFLC and Ac-MFLC were collected by ProtoXRD (USA) diffractometer using $\mathrm{Cu} K \alpha(40 \mathrm{kV} / 40 \mathrm{~mA})$ radiation $(\lambda=1.54060)$ between $2 \theta=0^{\circ}$ and $60^{\circ}$ with step size $2 \theta=0.02^{\circ}$.

\subsection{The X-ray photoelectron Spectroscopy (XPS)}

XPS of the MFLC and Ac-MFLC were conducted using a Kratos Axis Ultra Hybrid. X-ray source run at $15 \mathrm{~mA}$, emission at $225 \mathrm{~W}$. The pass energies of low and high resolution were 80 $\mathrm{eV}$ and $20 \mathrm{eV}$, respectively. The quantification of carbon bonds of MFLC and Ac-MFLC was carried out by fitting the $\mathrm{C} 1 \mathrm{~s}$ high resolution spectra. The binding energy scale of $(\mathrm{C}-\mathrm{C})$ was 
shifted to $284.8 \mathrm{eV}$. The degree of surface substitution (DSS) was calculated from the peak areas using Equation (1): [30]

$D S S=\frac{C_{\text {acetyl }}}{C_{\text {cell }} / 6}$

where $C_{\text {acetyl }}$ is the atomic concentration of acetyl groups $(\mathrm{O}-\mathrm{C}=\mathrm{O})$ after acetylation, and $\underline{C}_{\text {cell }} \underline{\text { is }}$ the atomic concentration of $(\mathrm{C}-\mathrm{O}+\mathrm{O}-\mathrm{C}-\mathrm{O})$ group in cellulose or lignocellulose for MFC and MFLC, respectively.

\section{Characterization of Biocomposites}

The biocomposite films were cut into rectangles $(100 \mathrm{~mm} \times 10 \mathrm{~mm} \times 50 \mu \mathrm{m})$ and their tensile properties determined using an Instron 5544 Universal Testing Machine equipped with a $100 \mathrm{~N}$ load cell; the jaw separation was $50 \mathrm{~mm}$ and the rate of displacement was $5 \mathrm{~mm} \mathrm{~s}^{-1}$. Thermal behaviours of PLA and Ac-MFLC biocomposites were investigated using Differential Scanning Calorimeter (DSC Q100, TA Instruments) in $\mathrm{N}_{2}$ atmosphere. A heating/cooling/heating cycle was carried out for characterizations. Approximately $3 \mathrm{mg}$ of samples were heated between 0 and $250{ }^{\circ} \mathrm{C}$ at $10{ }^{\circ} \mathrm{C} \mathrm{min}^{-1}$ heating and cooling rate. The crystallinity of the biocomposites was calculated using Equation (2): [31]

$X_{c}=\frac{\Delta H_{m}}{\Delta H_{m}^{\mathrm{o}} \omega} \times 100$

where $X_{c}$ is the crystallinity (\%), $\triangle H_{m}$ is the melting enthalpy, $\triangle H_{m}^{\circ}$ is the melting enthalpy of $100 \%$ crystalline PLA sample (assumed to be $93.7 \mathrm{~J} \mathrm{~g}^{-1}$ ) and $\omega$ is the weight fraction of PLA in the composite.

\section{Results}

\subsection{Morphology and Dispersibility}

The initial diameter of CTMP fibres was $27 \mu \mathrm{m}$ (Table S2). After fibrillation process, the diameter of isolated individual cellulose microfibrils (MFLC) were measured from image analysis of scanning electron micrographs as being in the range $40 \mathrm{~nm}$ to $400 \mathrm{~nm}$, indicating 
successful fibrillation of the CTMP fibres during the homogenization process (Fig. 2a). Red arrows numbered 1 and 2 show the MFLC with nanometer and submicron sizes, respectively. In addition to MFLC, globular-shaped particles were observed on microfibrils, which are marked by red arrows numbered 3, which are likely to be lignin particles; similar morphological structures were reported in previous studies $[27,32,33]$. This fibrillation technique was successfully used for the isolation of MFC with a narrow distribution of diameters from lyocell fibres in the literature [34,35]; we note that these fibres consist of pure reconstituted cellulose. Here, we observed rather broad distribution of microfibril diameters, which can be attributed to our source fibres being natural and to their appreciable hemicellulose and lignin content. Heating the materials above the glass transition temperature of lignin softens the hemicellulose/lignin matrix, facilitating the fibrillation of cellulose microfibrils [36]. However, fibrillation was carried out without any heat or chemical pre-treatment in our study, perhaps favouring the non-uniform morphology and cross-linked MFLC/lignin complex structures observed. The SEM image of Ac-MFLC (Fig. 2b) shows that there was no significant change on the morphology of microfibrils after acetylation. MFLC protected its highly fibrillated structure; however, increasing the hydrophobicity caused the agglomeration of MFLC when it deposited onto the hydrophilic mica disk [37].

The dispersibility of freeze-dried MFLC and Ac-MFLC was observed in water and three different solvents, namely dimethylformamide (DMF), tetrahydrofuran (THF) and chloroform with different polarities and dielectric constants (Fig. 2d). MFLC could be homogeneously dispersed in water; however, it quickly precipitated at the bottom of solution in all organic solvents. After introducing the acetyl groups, and decreasing the polarity of microfibrils, AcMFLC sedimented in water, whereas good dispersion of Ac-MFLC occurred in all organic solvents without any observable sedimentation. Ac-MFLC formed a clear and transparent suspension in all organic solvents, especially in DMF and chloroform, as the result of acetylated surface of MFLC, which enables the dispersion of microfibrils in organic solvents by preventing the possible hydrogen bonding between adjacent microfibrils [37]. 

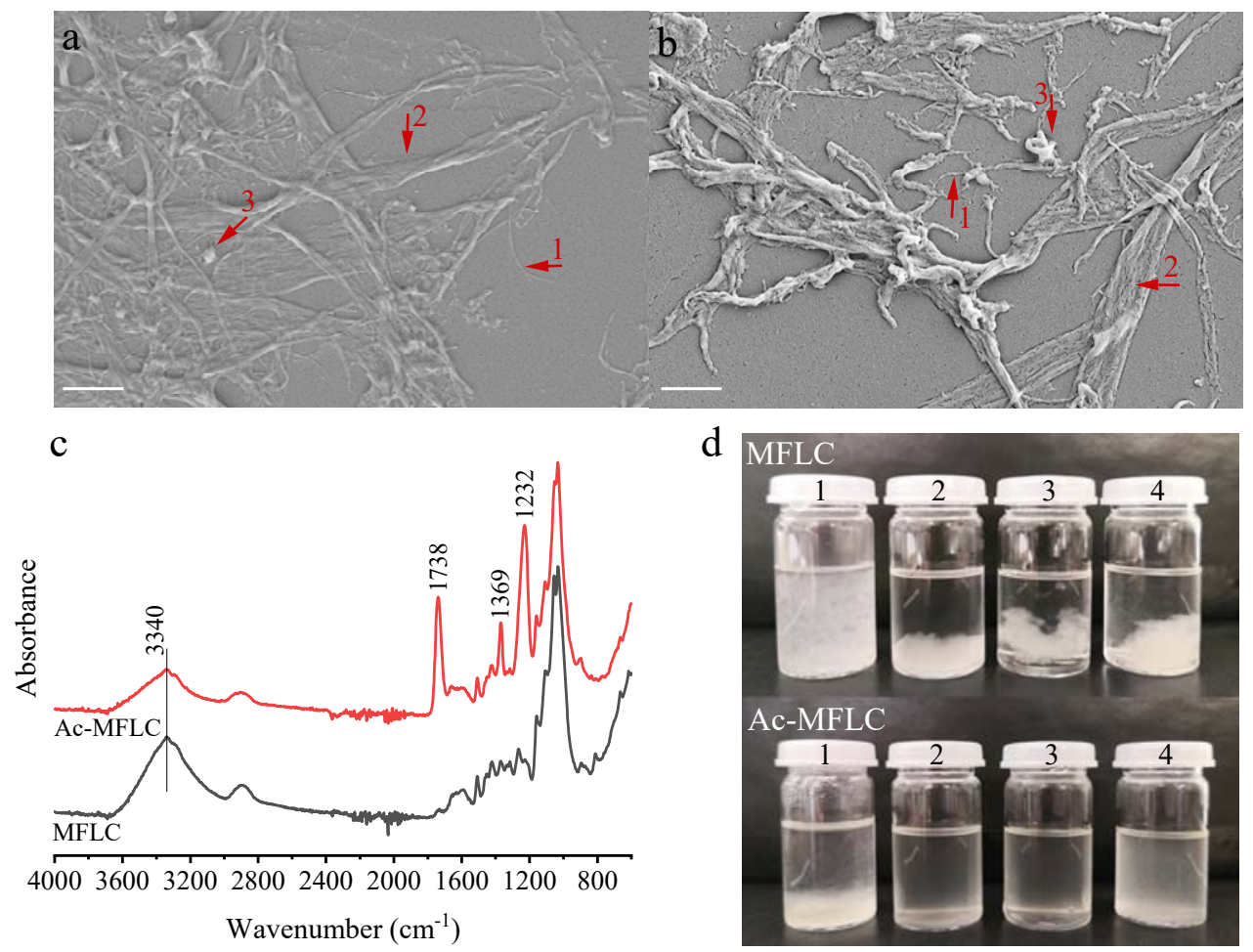

d MFLC

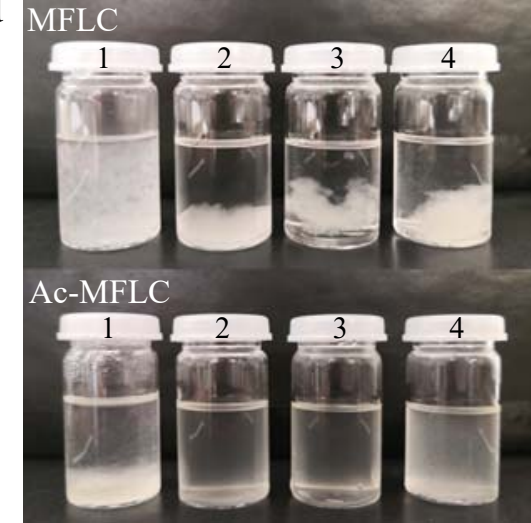

Fig. 2. SEM images of MFLC (a) and Ac-MFLC (b). Scale bar is $1 \mu \mathrm{m}$. FTIR absorbance of MFLC and Ac-MFLC (c), dispersibility of MFLC (upper image) and Ac-MFLC (lower image)

(d) in water (1), N,N-dimethyl formamide (2), chloroform (3) and tetrahydrofuran (4).

\subsection{Chemical Analysis}

The chemical structure of MFLC and Ac-MFLC was investigated by FTIR, XPS and XRD in order to determine the efficiency of the acetylation and the crystalline structure of MFLC. The FTIR spectra of MFLC and Ac-MFLC are shown in Fig. 2c. MFLC exhibited characteristic cellulose-I spectra possessing strong peaks at around $3340 \mathrm{~cm}^{-1}$ and $1035 \mathrm{~cm}^{-1}$, which are attributed to the $(-\mathrm{OH})$ and $(\mathrm{C}-\mathrm{O})$ stretching, respectively. However, two additional peaks which are absent in the cellulose-I spectra were observed at $1508 \mathrm{~cm}^{-1}$ and $1592 \mathrm{~cm}^{-1}$ indicating $(\mathrm{C}=\mathrm{C})$ and $(\mathrm{C}-\mathrm{H})$ skeletal vibrations in phenyl groups of the characteristic aromatic lignin $[38,39]$. The structural change of MFLC was verified by appearance of three new peaks 
referring to attached acetyl group onto cellulose after acetylation. Those three new peaks appeared at $1738 \mathrm{~cm}^{-1}, 1369 \mathrm{~cm}^{-1}$ and $1232 \mathrm{~cm}^{-1}$ which are associated with carbonyl esters (-COO-), (-CH) and (C-O) stretching of acetyl group, respectively. The hydroxyl stretching vibration at $3340 \mathrm{~cm}^{-1}$ decreased after acetylation confirming the successful esterification of MFLC.

The surface chemical compositions and the quantitative evaluation of DSS of Ac-MFLC were determined using XPS. The survey spectra (Fig. S1) showed only $\mathrm{C} 1$ and $\mathrm{O} 1$ peaks at $285 \mathrm{eV}$ and $533 \mathrm{eV}$, respectively. It reveals that no potassium peak observed on the spectra, confirming that the unreacted catalyst was removed completely during the rinsing and washing stages after acetylation. Fig. 3 shows the high resolution C1s spectra giving information about carbon chemistry of microfibrils. MFLC exhibited characteristic carbon peaks at 285, 286.5 and 288 eV, which are attributed to (C-C), (C-O) and (O-C-O) bonds, respectively (Fig. 3a) [40]. Furthermore, it exhibited a small peak at $289 \mathrm{eV}$ associated with the $(\mathrm{O}-\mathrm{C}=\mathrm{O})$ bond characteristic of the hemicellulose, xylan [41]. The intensity of this peak increased due to the introduction of ester groups after acetylation of MFLC (Fig. 3b) [42]. The relative peak areas of MFLC and Ac-MFLC are listed in Table S3. The peak area of (C-C) increased with the acetylation; however, the peaks area of (C-O) and (O-C-O) decreased due to acetyl substitution of $(-\mathrm{OH})$ groups with $(\mathrm{O}-\mathrm{C}=\mathrm{O})$ groups. The degree of surface substitution (DSS) was calculated as 1.02 from the XPS peaks area, showing the rapid acetylation mechanism of MFLC. 

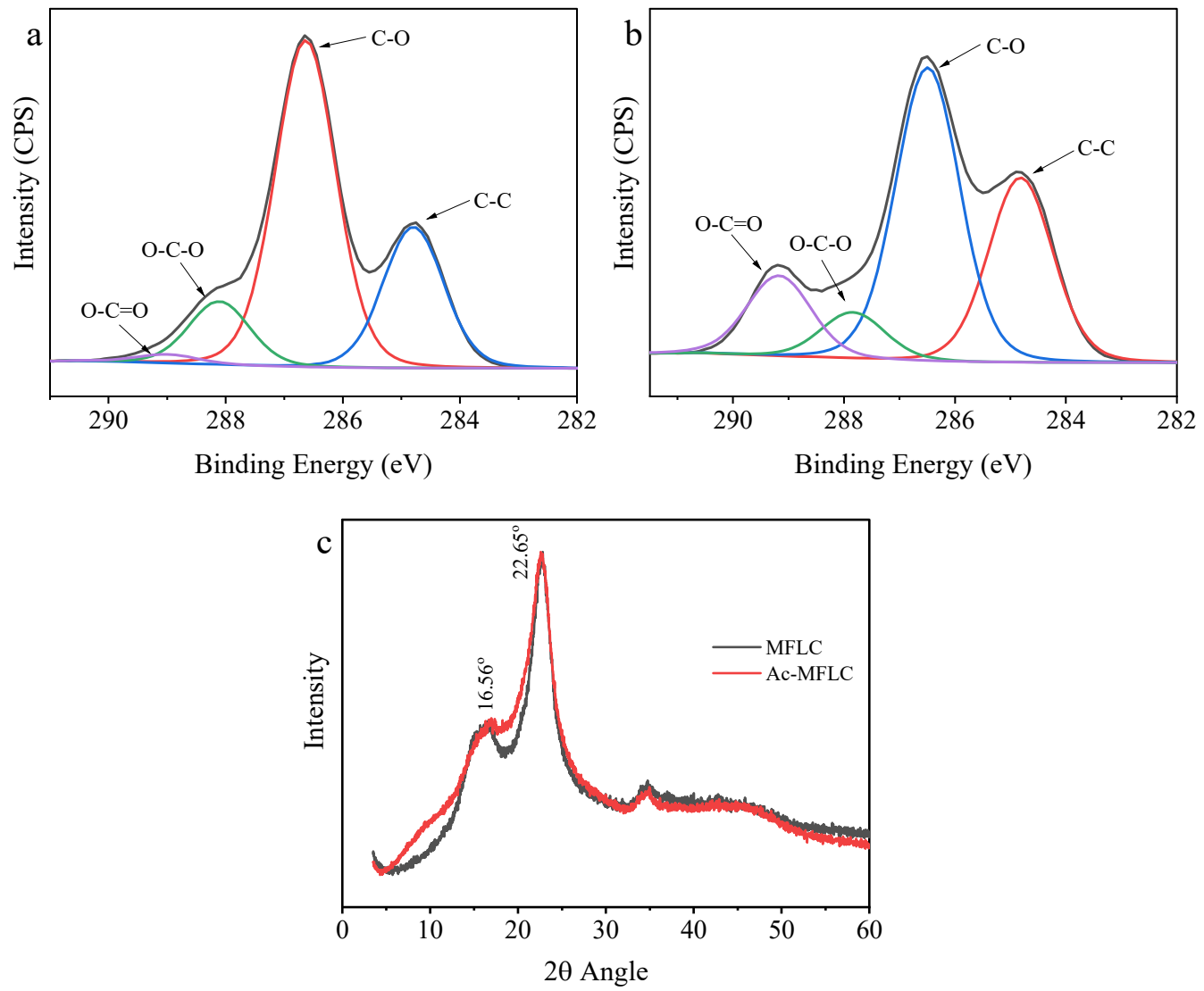

Fig. 3. XPS analysis of MFLC (a) and Ac-MFLC (b). XRD spectra of MFLC and Ac-MFLC (c).

We carried out the surface acetylation of MFC isolated from bleached softwood pulp also, using the same mechanical treatments as for MFLC. The same acetylation technique was performed to compare the efficiency of the acetylation reaction between acetylated MFC (Ac-MFC) and AcMFLC. High-resolution C1s spectra of MFC and Ac-MFC and its relative peaks area are shown in Fig. S2 and Table S3, respectively. The acetylation results showed that MFLC exhibited $27 \%$ higher DSS than MFC. This shows clearly that the high lignin and hemicellulose content of MFLC (Table S1) increased the acetylation efficiency due to the different reactivities of cell wall polymers [43]. Lignin and hemicellulose exhibit higher reactivity than cellulose during the modification with acetic anhydride, since cellulose has fewer accessible hydroxyl groups than lignin and hemicellulose due to its high crystallinity [44,45]. Therefore, MFLC exhibited higher 
DSS than MFC as its microfibril surface is covered with more accessible lignin and hemicellulose matrix which could be rapidly modified using AA/DMF/ $\mathrm{K}_{2} \mathrm{CO}_{3}$ system. The effect of acetylation on the crystalline structure of MFLC was evaluated using X-ray diffraction (XRD) analysis. Fig. 3c shows the diffraction pattern of MFLC and Ac-MFLC. MFLC exhibited characteristic cellulose diffraction peaks $2 \theta$ angles at $16.6^{\circ}, 22.7^{\circ}$ and $34.8^{\circ}$ indicating 101, 002 and 004 lattice planes, respectively [46]. The diffraction pattern of AcMFLC did not change considerably after acetylation compared to that of un-modified MFLC. The intensity of peaks was maintained after acetylation, indicating that crystalline structure was preserved during the modification. However, Ac-MFLC exhibited slightly broader peaks than MFLC at $16.6^{\circ}$ and $22.7^{\circ}$, which is consistent with the increased interlayer distance of individual crystalline cellulose resulting in acetylation of the cellulose chain [47]. The preserved cellulose crystalline structure showed that the inner crystal layers of cellulose were unmodified during acetylation. This is due to the surface modification of MFLC, especially the hemicellulose/lignin complex structure surrounding the cellulose microfibrils. Furthermore, $\mathrm{K}_{2} \mathrm{CO}_{3}$ catalyzed esterification $[29,48,49]$ offers a more moderate condition for the modification of nanocellulose compared to pyridine [50], citric acid [51] and sulfuric acid [15] catalyzed esterifications, disrupting the crystalline interlayer of cellulose during the reaction by excessive acetylation resulted in increased accessible hydroxyl groups [52]. Taken together, the FTIR, XPS and XRD results showed that the surface of MFLC was successfully acetylated without decrystallization of cellulose microfibrils as the result of modification of more reactive hemicelluloses/lignin complex on the surface of MFLC.

\subsection{Properties of Biocomposites}

The reinforcing capacity of Ac-MFLC was determined by measuring the mechanical performance of biocomposites in which Ac-MFLC content was adjusted between $0.5 \%$ and $5 \%$. The mechanical properties of biocomposites are shown in Fig. 4a. The error bars present $95 \%$ confidence intervals on the data, and the maximum coefficients of variation of tensile 
strength and Young's modulus across the samples were $6 \%$ and $9 \%$, respectively. The addition of Ac-MFLC clearly increased the tensile strength and Young's modulus of PLA, which shows the reinforcing ability of Ac-MFLC. Low Ac-MFLC content (0.5\% and $1 \%)$ significantly improved both tensile strength and Young's modulus, which can be attributed to good stresstransfer at the interface with Ac-MFLC, and uniform dispersion of Ac-MFLC in PLA [47]. As the hydrophobicity of MFLC improved after acetylation, its dispersion in PLA and the dissolving medium chloroform increased. The addition of $1 \%$ Ac-MFLC increased the tensile strength and Young's modulus of PLA by $37 \%$ and $28 \%$, respectively. At the higher levels of addition, both tensile strength and Young's modulus reached a plateau; the data suggest a small decrease in tensile strength with the addition of $5 \%$ Ac-MFLC, which may be attributed to increased fibre-fibre interactions resulting in insufficient wetting and a decrease of stresstransfer efficiency between Ac-MFLC and PLA [47]. 

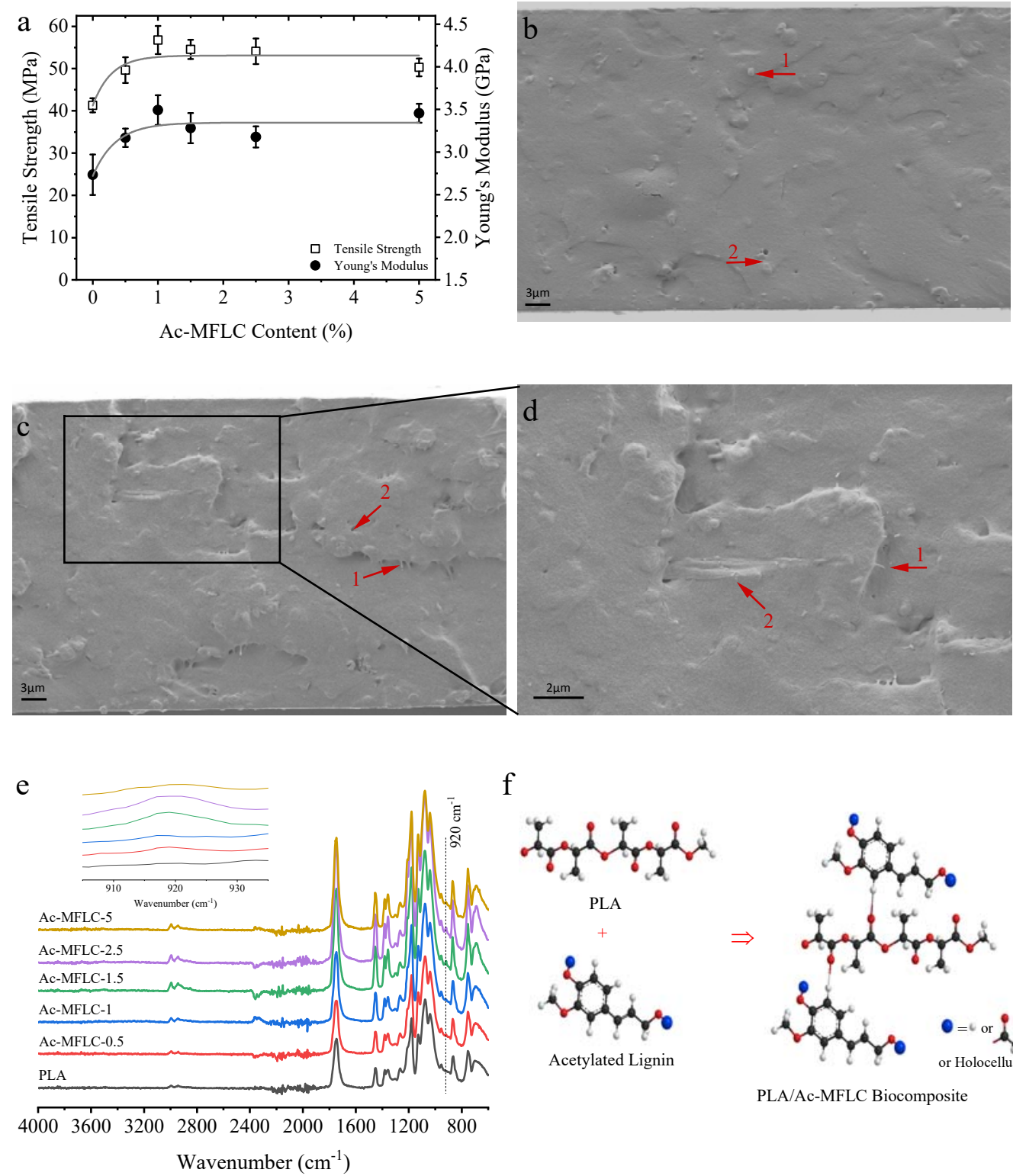

f
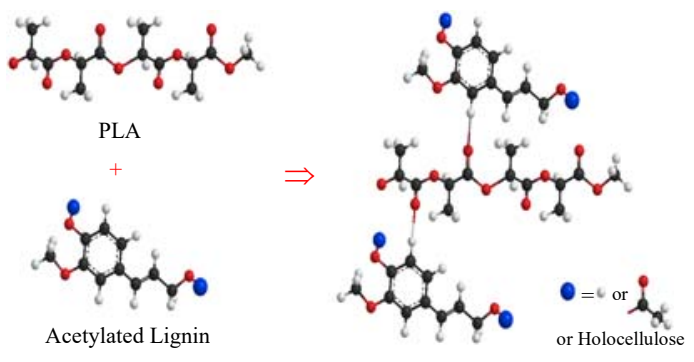

PLA/Ac-MFLC Biocomposite

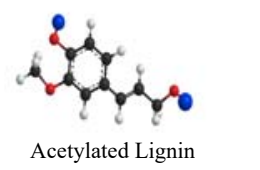

Wavenumber $\left(\mathrm{cm}^{-1}\right)$

Fig. 4. The mechanical performance of biocomposites with different Ac-MFLC content (a).

SEM images of the fracture surface of neat PLA (b) and $1 \%$ Ac-MFLC reinforced

biocomposite with different magnification (c-d). FTIR spectra of neat PLA and biocomposites

(e). The interaction mechanism between Ac-MFLC and PLA in biocomposites (f).

The fracture surface morphologies of the PLA and biocomposites are shown in Fig. 4b-d. Neat PLA showed a smooth surface indicating the brittle fracture (Fig. 4b). Arrow number 1 shows 
the white spot which could be the result of the initiation of fibril formation. However, fibrils could not propagate due to the brittleness of the PLA. Small voids were also observed (arrows numbered 2) on both neat PLA and biocomposite. After adding Ac-MFLC, the fracture surface of PLA exhibited a rough and coarse structure, suggesting at ductile fracture (Fig. 4c) [53]. Furthermore, bridging fibrils (arrow 1) were observed as the result of craze formation of PLA, due to plastic deformation prior to final fracture. High magnification SEM images (Fig. 4d) of the biocomposite show submicron sized fibrils (arrow 2) broken during the fracture without pulling out, indicates a good interfacial bonding between PLA and Ac-MFLC.

FTIR analysis of PLA and Ac-MFLC biocomposites was used to determine the interactions between PLA and Ac-MFLC (Fig. 4e). Biocomposites exhibited similar FTIR spectra to neat PLA. However, the intensities of the peaks slightly increased at 1076, 1747, 2942 and $2994 \mathrm{~cm}^{-}$ ${ }^{1}$, associated with $(\mathrm{C}-\mathrm{O}),(\mathrm{C}=\mathrm{O})$, symmetric and asymmetric $(\underline{-\mathrm{CH}})$ bending, respectively $[54,55]$. The increased intensity of these peaks could be due to the presence of $(\mathrm{C}-\mathrm{O}),(\mathrm{C}=\mathrm{O})$ and (-CH) groups in the chemical structure of Ac-MFLC [56]. Similar increase in the intensity of these peaks was reported in previous studies in which PLA biocomposites reinforced with acetylated nanocellulose $[50,57,58]$. The interactions between cellulosic fibres and PLA matrix influence the carbonyl $(\mathrm{C}=\mathrm{O})$ bending of which peak broadening and/or location shifting indicate the interactions between carbonyl oxygen of PLA and hydroxyl hydrogen of cellulose [59,60]. No carbonyl peak shifting at $1747 \mathrm{~cm}^{-1}$ and unbound hydroxyl stretching at $3300 \mathrm{~cm}^{-1}$ were observed in the FTIR spectra of biocomposites (Fig. 4e), since the hydroxyl groups on the surface of MFLC were substituted with acetyl groups. However, a new peak was observed at $920 \mathrm{~cm}^{-1}$ ascribed to the out of plane aromatic (C-H) bending (Fig. 4e inner image) [61]. This could be due to the hydrogen bond between the aromatic hydrogen of lignin and the carboxyl oxygen of PLA; the mechanism is shown in Fig. 4f. This confirms the strong interactions between Ac-MFLC and PLA. As the surface of MFLC is covered with hemicellulose/lignin complex structure connected to cellulose microfibrils via hydrogen bonds, the aromatic lignin 
acted as a bridge between microfibrils and PLA matrix. However, the biocomposite with $5 \%$ Ac-MFLC content exhibited weak peak intensity at $920 \mathrm{~cm}^{-1}$ compared to other biocomposites. It might be due to the fibre-fibre interactions decreasing the fibre-matrix interface, and leading to the low mechanical performance.
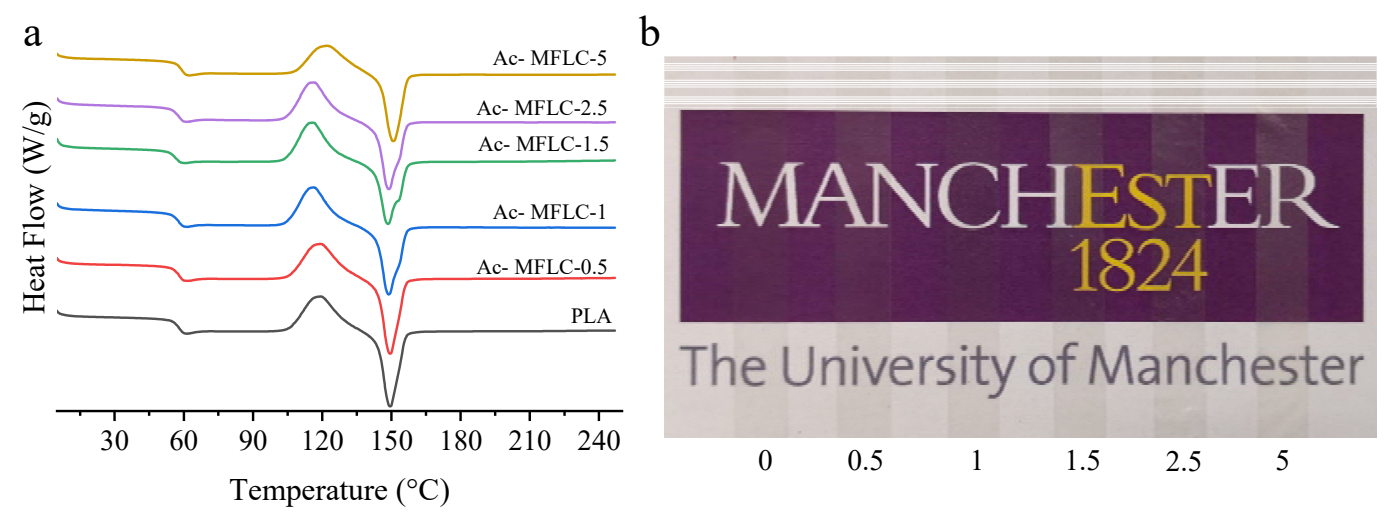

Fig. 5. (a) DSC thermogram of PLA and bicocomposites (b). Photograph of solvent-cast biocomposite films showing transparency at different addition levels of Ac-MFLC, as indicated below.

Thermal behaviour of PLA and biocomposites was investigated using DSC analysis (Fig. 5).

The characteristic DSC data such as glass transition temperature $\left(T_{\mathrm{g}}\right)$, crystallization temperature $\left(T_{c}\right)$ and melting temperature $\left(T_{m}\right)$, melting enthalpy $\left(\triangle H_{m}\right)$ and degree of crystallization, which were calculated from DSC thermogram, are reported in Table S4. The $T_{g}$ of neat PLA was $55.6{ }^{\circ} \mathrm{C}$, and the introduction of Ac-MFLC slightly increased the $T_{g}$ by around 1 to $2{ }^{\circ} \mathrm{C}$ depending on the Ac-MFLC content in the biocomposites. This is due to the restricted amorphous chain mobility, causing high energy requirement for the transformation of the biocomposites [50]. Furthermore, the $T_{c}, T_{m}$ and $X_{c}$ of PLA increased significantly with the addition of Ac-MFLC due to the nucleating effect of microfibrils. However, the $5 \%$ Ac-MFLC added biocomposites exhibited lower $X_{c}$ than other biocomposites, which might be result of microfibril aggregation resulting in decrease the number of nucleating sites [62]. Overall, the 
improved Ac-MFLC dispersibility and its strong interactions with PLA increased the thermal properties of the biocomposites. This result can be supported by the appearance of biocomposites, exhibiting high transparency with the benefit of the improved dispersion of AcMFLC in PLA matrix (Fig. 5b).

\section{Conclusions}

In this study, we isolated high lignin containing MFLC, and modified its surface using acetylation. The chemical analysis of acetylated MFLC demonstrated that MFLC was successfully acetylated without damaging the crystalline structure. MFLC exhibited higher DSS compared to lignin-free MFC after acetylation. This indicates that the high lignin and hemicellulose content of MFLC promoted the acetylation reaction performed with acetic anhydride. The generated Ac-MFLC was used as a reinforcing agent in a PLA matrix to make biocomposite films using a solvent casting method. The reduced polarity of MFLC improved its dispersibility and the quality of the interface with PLA matrix. The addition of low weight percentage of Ac-MFLC improved both the mechanical performance and thermal properties of neat PLA. Moreover, Ac-MFLC significantly increased the crystallinity of PLA, which we attribute to the Ac-MFLC promoting nucleation.

We suggest that Ac-MFLC could be used as a promising reinforcing agent in other types of polyester with the benefit of its decreased polarity which might lead to improvement of its dispersibility and interfacial bonding with polyesters.

\section{Acknowledgements}

We acknowledge the valuable support of Enrique Lallana-Ozores for freeze-drying, Ben Spencer for XPS analysis, and John Warren for XRD analysis of microfibrils. We also acknowledge the scholarship provided by the Republic of Turkey - Ministry of National Education, and Turkish Forestry Service.

\section{Appendix A. Supplementary data}

The following are the supplementary are provided: 
Chemical composition of CTMP, fibre dimensions of CTMP, XPS survey spectra of MFLC and Ac-MFLC, XPS relative peaks area of all microfibrils, XPS analysis of MFC and Ac-MFC, DSC data of neat PLA and biocomposites.

Notes

The authors declare no competing financial interest.

\section{REFERENCES}

[1] Y. Zhu, C. Romain, C.K. Williams, Sustainable polymers from renewable resources, Nature. 540 (2016) 354-362. http://dx.doi.org/10.1038/nature21001.

[2] R.B. Valapa, G. Pugazhenthi, V. Katiyar, Fabrication and characterization of sucrose palmitate reinforced poly(lactic acid) bionanocomposite films, J. Appl. Polym. Sci. 132 (2015) n/a-n/a. https://doi.org/10.1002/app.41320.

[3] Y. Kim, J.S. Kim, S.Y. Lee, R.L. Mahajan, Y.T. Kim, Exploration of hybrid nanocarbon composite with polylactic acid for packaging applications, Int. J. Biol. Macromol. 144 (2020) 135-142. https://doi.org/10.1016/j.ijbiomac.2019.11.239.

[4] W. Yang, E. Fortunati, F. Dominici, J.M. Kenny, D. Puglia, Effect of processing conditions and lignin content on thermal, mechanical and degradative behavior of lignin nanoparticles/polylactic (acid) bionanocomposites prepared by melt extrusion and solvent casting, Eur. Polym. J. 71 (2015) 126-139.

https://doi.org/10.1016/j.eurpolymj.2015.07.051.

[5] Z. Wang, Z. Yao, J. Zhou, M. He, Q. Jiang, A. Li, S. Li, M. Liu, S. Luo, D. Zhang, Improvement of polylactic acid film properties through the addition of cellulose nanocrystals isolated from waste cotton cloth, Int. J. Biol. Macromol. 129 (2019) 878886. https://doi.org/10.1016/j.ijbiomac.2019.02.021.

[6] K.I. Ku Marsilla, C.J.R. Verbeek, Modification of poly(lactic acid) using itaconic anhydride by reactive extrusion, Eur. Polym. J. 67 (2015) 213-223. 
https://doi.org/10.1016/j.eurpolymj.2015.03.054.

[7] J. Bao, R. Chang, G. Shan, Y. Bao, P. Pan, Promoted Stereocomplex Crystallization in Supramolecular Stereoblock Copolymers of Enantiomeric Poly(Lactic Acid)s, Cryst. Growth Des. 16 (2016) 1502-1511. https://doi.org/10.1021/acs.cgd.5b01627.

[8] P. Pan, J. Bao, L. Han, Q. Xie, G. Shan, Y. Bao, Stereocomplexation of high-molecularweight enantiomeric poly(lactic acid)s enhanced by miscible polymer blending with hydrogen bond interactions, Polymer (Guildf). 98 (2016) 80-87. https://doi.org/10.1016/j.polymer.2016.06.014.

[9] D.O. Castro, Z. Karim, L. Medina, J.O. Häggström, F. Carosio, A. Svedberg, L. Wågberg, D. Söderberg, L.A. Berglund, The use of a pilot-scale continuous paper process for fire retardant cellulose-kaolinite nanocomposites, Compos. Sci. Technol. 162 (2018) 215-224. https://doi.org/10.1016/j.compscitech.2018.04.032.

[10] a Iwatake, M. Nogi, H. Yano, Cellulose nanofiber-reinforced polylactic acid, Compos. Sci.Technol. (2008). https://doi.org/10.1016/j.compscitech.2008.03.006.

[11] J. Su, W.K.J. Mosse, S. Sharman, W.J. Batchelor, G. Garnier, Effect of tethered and free microfibrillated cellulose (MFC) on the properties of paper composites, Cellulose. 20 (2013) 1925-1935. https://doi.org/10.1007/s10570-013-9955-x.

[12] C. Zhao, L.H. Mark, M. Alshrah, I. Soltani, P.C. Lee, C.B. Park, Challenge in manufacturing nanofibril composites with low matrix viscosity: Effects of matrix viscosity and fibril content, Eur. Polym. J. 121 (2019) 109310. https://doi.org/10.1016/j.eurpolymj.2019.109310.

[13] K.C. Hung, T.L. Wu, Y.L. Chen, J.H. Wu, Assessing the effect of wood acetylation on mechanical properties and extended creep behavior of wood/recycled-polypropylene composites, Constr. Build. Mater. 108 (2016) 139-145. 
https://doi.org/10.1016/j.conbuildmat.2016.01.039.

[14] T. Joffre, K. Segerholm, C. Persson, S.L. Bardage, C.L. Luengo Hendriks, P. Isaksson, Characterization of interfacial stress transfer ability in acetylation-treated wood fibre composites using X-ray microtomography, Ind. Crops Prod. 95 (2017) 43-49. https://doi.org/10.1016/j.indcrop.2016.10.009.

[15] A. Tripathi, M. Ago, S.A. Khan, O.J. Rojas, Heterogeneous Acetylation of Plant Fibers into Micro- and Nanocelluloses for the Synthesis of Highly Stretchable, Tough, and Water-Resistant Co-continuous Filaments via Wet-Spinning, ACS Appl. Mater. Interfaces. (2018). https://doi.org/10.1021/acsami.8b17790.

[16] A. Sato, D. Kabusaki, H. Okumura, T. Nakatani, F. Nakatsubo, H. Yano, Surface modification of cellulose nanofibers with alkenyl succinic anhydride for high-density polyethylene reinforcement, Compos. Part A Appl. Sci. Manuf. 83 (2016) 72-79. https://doi.org/10.1016/j.compositesa.2015.11.009.

[17] M.B. Agustin, F. Nakatsubo, H. Yano, The thermal stability of nanocellulose and its acetates with different degree of polymerization, Cellulose. (2016). https://doi.org/10.1007/s10570-015-0813-x.

[18] A. Ämmälä, O. Laitinen, J.A. Sirviö, H. Liimatainen, Key role of mild sulfonation of pine sawdust in the production of lignin containing microfibrillated cellulose by ultrafine wet grinding, Ind. Crops Prod. 140 (2019) 111664. https://doi.org/10.1016/j.indcrop.2019.111664.

[19] Y. Chen, D. Fan, Y. Han, S. Lyu, Y. Lu, G. Li, F. Jiang, S. Wang, Effect of high residual lignin on the properties of cellulose nanofibrils/films, Cellulose. 25 (2018) 6421-6431. https://doi.org/10.1007/s10570-018-2006-x.

[20] H. Yousefi, V. Azari, A. Khazaeian, Direct mechanical production of wood nanofibers 
from raw wood microparticles with no chemical treatment, Ind. Crops Prod. 115 (2018) 26-31. https://doi.org/10.1016/j.indcrop.2018.02.020.

[21] Y. Jiang, X. Liu, Q. Yang, X. Song, C. Qin, S. Wang, K. Li, Effects of residual lignin on composition, structure and properties of mechanically defibrillated cellulose fibrils and films, Cellulose. 26 (2019) 1577-1593. https://doi.org/10.1007/s10570-018-02229-4.

[22] Y. Peng, S.S. Nair, H. Chen, N. Yan, J. Cao, Effects of Lignin Content on Mechanical and Thermal Properties of Polypropylene Composites Reinforced with Micro Particles of Spray Dried Cellulose Nanofibrils, ACS Sustain. Chem. Eng. 6 (2018) 11078-11086. https://doi.org/10.1021/acssuschemeng.8b02544.

[23] H. Lu, L. Zhang, C. Liu, Z. He, X. Zhou, Y. Ni, A novel method to prepare lignocellulose nanofibrils directly from bamboo chips, Cellulose. 25 (2018) 7043-7051. https://doi.org/10.1007/s10570-018-2067-x.

[24] S.H. Osong, S. Norgren, P. Engstrand, An approach to produce nano-ligno-cellulose from mechanical pulp fine materials, Nord. Pulp Pap. Res. J. 28 (2013) 472-479. https://doi.org/10.3183/npprj-2013-28-04-p472-479.

[25] E. Oliaei, P.A. Lindén, Q. Wu, F. Berthold, L. Berglund, T. Lindström, Microfibrillated lignocellulose (MFLC) and nanopaper films from unbleached kraft softwood pulp, Cellulose. (2019) 1-17. https://doi.org/10.1007/s10570-019-02934-8.

[26] M. Farooq, T. Zou, G. Riviere, M.H. Sipponen, M. Österberg, Strong, Ductile, and Waterproof Cellulose Nanofibril Composite Films with Colloidal Lignin Particles, Biomacromolecules. 20 (2019) 693-704. https://doi.org/10.1021/acs.biomac.8b01364.

[27] E. Rojo, M.S. Peresin, W.W. Sampson, I.C. Hoeger, J. Vartiainen, J. Laine, O.J. Rojas, Comprehensive elucidation of the effect of residual lignin on the physical, barrier, mechanical and surface properties of nanocellulose films, Green Chem. (2015). 
https://doi.org/10.1039/c4gc02398f.

[28] S. Herzele, S. Veigel, F. Liebner, T. Zimmermann, W. Gindl-Altmutter, Reinforcement of polycaprolactone with microfibrillated lignocellulose, Ind. Crops Prod. (2016). https://doi.org/10.1016/j.indcrop.2015.12.051.

[29] N.S. Çetin, P. Tingaut, N. Özmen, N. Henry, D. Harper, M. Dadmun, G. Sèbe, Acetylation of cellulose nanowhiskers with vinyl acetate under moderate conditions, Macromol. Biosci. (2009). https://doi.org/10.1002/mabi.200900073.

[30] F. Dong, M. Yan, C. Jin, S. Li, Characterization of type-II acetylated cellulose nanocrystals with various degree of substitution and its compatibility in PLA films, Polymers (Basel). (2017). https://doi.org/10.3390/polym9080346.

[31] A.P. Mathew, K. Oksman, M. Sain, The effect of morphology and chemical characteristics of cellulose reinforcements on the crystallinity of polylactic acid, J. Appl. Polym. Sci. (2006). https://doi.org/10.1002/app.23346.

[32] S.S. Nair, N. Yan, Effect of high residual lignin on the thermal stability of nanofibrils and its enhanced mechanical performance in aqueous environments, Cellulose. (2015). https://doi.org/10.1007/s10570-015-0737-5.

[33] M. Herrera, K. Thitiwutthisakul, X. Yang, P. on Rujitanaroj, R. Rojas, L. Berglund, Preparation and evaluation of high-lignin content cellulose nanofibrils from eucalyptus pulp, Cellulose. (2018). https://doi.org/10.1007/s10570-018-1764-9.

[34] S. Tanpichai, W.W. Sampson, S.J. Eichhorn, Stress-transfer in microfibrillated cellulose reinforced poly(lactic acid) composites using Raman spectroscopy, Compos. Part A Appl. Sci. Manuf. 43 (2012) 1145-1152. https://doi.org/10.1016/J.COMPOSITESA.2012.02.006.

[35] S. Tanpichai, W.W. Sampson, S.J. Eichhorn, Stress transfer in microfibrillated cellulose 
reinforced poly(vinyl alcohol) composites, Compos. Part A Appl. Sci. Manuf. 65 (2014) 186-191. https://doi.org/10.1016/J.COMPOSITESA.2014.06.014.

[36] A. Tripathi, A. Ferrer, S.A. Khan, O.J. Rojas, Morphological and Thermochemical Changes upon Autohydrolysis and Microemulsion Treatments of Coir and Empty Fruit Bunch Residual Biomass to Isolate Lignin-Rich Micro- and Nanofibrillar Cellulose, ACS Sustain. Chem. Eng. (2017). https://doi.org/10.1021/acssuschemeng.6b02838.

[37] P. Tingaut, T. Zimmermann, F. Lopez-Suevos, Synthesis and characterization of bionanocomposites with tunable properties from poly(lactic acid) and acetylated microfibrillated cellulose, Biomacromolecules. (2010). https://doi.org/10.1021/bm901186u.

[38] J. Rodrigues, O. Faix, H. Pereira, Determination of lignin content of Eucalyptus globulus wood using FTIR spectroscopy, Holzforschung. (1998). https://doi.org/10.1515/hfsg.1998.52.1.46.

[39] A. Winter, L. Andorfer, S. Herzele, T. Zimmermann, B. Saake, M. Edler, T. Griesser, J. Konnerth, W. Gindl-Altmutter, Reduced polarity and improved dispersion of microfibrillated cellulose in poly(lactic-acid) provided by residual lignin and hemicellulose, J. Mater. Sci. (2017). https://doi.org/10.1007/s10853-016-0439-x.

[40] Huihong Yuan, Yoshiharu Nishiyama, Masahisa Wada, Shigenori Kuga, Surface Acylation of Cellulose Whiskers by Drying Aqueous Emulsion, Biomacromolecules. (2006). https://doi.org/10.1021/BM050828J.

[41] D. Ballner, S. Herzele, J. Keckes, M. Edler, T. Griesser, B. Saake, F. Liebner, A. Potthast, C. Paulik, W. Gindl-Altmutter, Lignocellulose Nanofiber-Reinforced Polystyrene Produced from Composite Microspheres Obtained in Suspension Polymerization Shows Superior Mechanical Performance, ACS Appl. Mater. Interfaces. (2016). https://doi.org/10.1021/acsami.6b01992. 
[42] Q. Xie, S. Wang, X. Chen, Y. Zhou, H. Fang, X. Li, S. Cheng, Y. Ding, Thermal stability and crystallization behavior of cellulose nanocrystals and their poly(l-lactide) nanocomposites: effects of surface ionic group and poly(d-lactide) grafting, Cellulose. (2018). https://doi.org/10.1007/s10570-018-2086-7.

[43] C.A.S. Hill, Wood Modification: Chemical, Thermal and Other Processes, 2006. https://doi.org/10.1002/0470021748.

[44] R. Rowell, R. Simonson, S. Hess, D. Plackett, D. Cronshaw, E. Dunningham, Acetyl Distribution in Acetylated Whole Wood and Reactivity of Isolated Wood Cell-Wall Components To Acetic Anhydride, Wood Fiber Sci. (1994).

[45] M. Jebrane, F. Pichavant, G. Sbe, A comparative study on the acetylation of wood by reaction with vinyl acetate and acetic anhydride, Carbohydr. Polym. (2011). https://doi.org/10.1016/j.carbpol.2010.07.035.

[46] C.M. Conrad, J.J. Creely, Thermal x-ray diffraction study of highly acetylated cotton cellulose, J. Polym. Sci. 58 (1962) 781-790. https://doi.org/doi:10.1002/pol.1962.1205816648.

[47] E. Abraham, D. Kam, Y. Nevo, R. Slattegard, A. Rivkin, S. Lapidot, O. Shoseyov, Highly Modified Cellulose Nanocrystals and Formation of Epoxy-Nanocrystalline Cellulose (CNC) Nanocomposites, ACS Appl. Mater. Interfaces. 8 (2016) 28086-28095. https://doi.org/10.1021/acsami.6b09852.

[48] G. Seibe, F. Ham-Pichavant, G. Pecastaings, Dispersibility and emulsion-stabilizing effect of cellulose nanowhiskers esterified by vinyl acetate and vinyl cinnamate, Biomacromolecules. (2013). https://doi.org/10.1021/bm400854n.

[49] J. Brand, G. Pecastaings, G. Sèbe, A versatile method for the surface tailoring of cellulose nanocrystal building blocks by acylation with functional vinyl esters, 
Carbohydr. Polym. 169 (2017) 189-197. https://doi.org/10.1016/j.carbpol.2017.03.077.

[50] N. Lin, J. Huang, P.R. Chang, J. Feng, J. Yu, Surface acetylation of cellulose nanocrystal and its reinforcing function in poly(lactic acid), Carbohydr. Polym. 83 (2011) 18341842. https://doi.org/https://doi.org/10.1016/j.carbpol.2010.10.047.

[51] J.A. Ávila Ramírez, C. Gómez Hoyos, S. Arroyo, P. Cerrutti, M.L. Foresti, Acetylation of bacterial cellulose catalyzed by citric acid: Use of reaction conditions for tailoring the esterification extent, Carbohydr. Polym. (2016). https://doi.org/10.1016/j.carbpol.2016.08.009.

[52] S. Kalia, S. Boufi, A. Celli, S. Kango, Nanofibrillated cellulose: Surface modification and potential applications, Colloid Polym. Sci. (2014). https://doi.org/10.1007/s00396013-3112-9.

[53] H. Kang, Y. Li, M. Gong, Y. Guo, Z. Guo, Q. Fang, X. Li, An environmentally sustainable plasticizer toughened polylactide, RSC Adv. (2018). https://doi.org/10.1039/c7ra13448g.

[54] B.W. Chieng, N.A. Ibrahim, W.M.Z.W. Yunus, M.Z. Hussein, Poly(lactic acid)/poly(ethylene glycol) polymer nanocomposites: Effects of graphene nanoplatelets, Polymers (Basel). (2014). https://doi.org/10.3390/polym6010093.

[55] L. Zhou, H. He, M. chun Li, S. Huang, C. Mei, Q. Wu, Enhancing mechanical properties of poly(lactic acid) through its in-situ crosslinking with maleic anhydride-modified cellulose nanocrystals from cottonseed hulls, Ind. Crops Prod. 112 (2018) 449-459. https://doi.org/10.1016/j.indcrop.2017.12.044.

[56] P. Dhar, S.M. Bhasney, A. Kumar, V. Katiyar, Acid functionalized cellulose nanocrystals and its effect on mechanical, thermal, crystallization and surfaces properties of poly (lactic acid) bionanocomposites films: A comprehensive study, Polymer 
(Guildf). 101 (2016) 75-92. https://doi.org/10.1016/j.polymer.2016.08.028.

[57] F. Lu, H. Yu, C. Yan, J. Yao, Polylactic acid nanocomposite films with spherical nanocelluloses as efficient nucleation agents: Effects on crystallization, mechanical and thermal properties, RSC Adv. (2016). https://doi.org/10.1039/c6ra02768g.

[58] C. Xu, J. Chen, D. Wu, Y. Chen, Q. Lv, M. Wang, Polylactide/acetylated nanocrystalline cellulose composites prepared by a continuous route: A phase interface-property relation study, Carbohydr. Polym. 146 (2016) 58-66. https://doi.org/10.1016/j.carbpol.2016.03.058.

[59] P. Qu, Y. Gao, G.F. Wu, L.P. Zhang, Nanocomposites of Poly(lactic acid) reinforced with cellulose nanofibrils, BioResources. 5 (2010) 1811-1823.

[60] B. Dogu, C. Kaynak, Behavior of polylactide/microcrystalline cellulose biocomposites: effects of filler content and interfacial compatibilization, Cellulose. 23 (2016) 611-622. https://doi.org/10.1007/s10570-015-0839-0.

[61] S. Beisl, P. Loidolt, A. Miltner, M. Harasek, A. Friedl, Production of micro- and nanoscale lignin from wheat straw using different precipitation setups, Molecules. (2018). https://doi.org/10.3390/molecules23030633.

[62] M. Perić, R. Putz, C. Paulik, Influence of nanofibrillated cellulose on the mechanical and thermal properties of poly(lactic acid), Eur. Polym. J. 114 (2019) 426-433.

https://doi.org/10.1016/j.eurpolymj.2019.03.014. 